\title{
Innovative Interior Designs for Urban Freight Distribution Using Light Rail Systems
}

\author{
James Kelly ${ }^{1} \cdot$ Marin Marinov ${ }^{1}$
}

Received: 8 May 2017/Revised: 8 November 2017/Accepted: 17 November 2017/Published online: 5 December 2017

(c) The Author(s) 2017. This article is an open access publication

\begin{abstract}
High levels of pollution and congestion in urban centres are an increasing concern for local councils in the UK. Heavy goods vehicles delivering urban freight to city centres are a leading cause of this problem. This paper discusses the concept of using light rail networks to deliver freight to city centres from surrounding businesses. Specifically, various innovative designs are considered for the interior of the metro carriage and developed into visual models using Autodesk Inventor software. A full evaluation of all the designs developed is completed, resulting in a proposed design for consideration. The conclusion reached is that the proposed interior design is viable and coincides with the future metro fleet designs and concepts.
\end{abstract}

Keywords Metro · Urban freight - Interior design ·

Autodesk Inventor · Tyne and Wear metro - Light rail ·

Urban environment

\section{Introduction}

Freight distribution is an important part of economic and national development in the UK [1]. The problem of increasing congestion and pollution in urban centres is a growing concern for urban centres in the UK. In 2015, 1.65 billion tonnes of goods were lifted by HGVs in the UK; this represented an increase of $11 \%$ compared with previous years;

Marin Marinov

marin.marinov@ncl.ac.uk

1 NewRail, Mechanical and Systems Engineering School, Newcastle University, Newcastle upon Tyne, UK

Editor: Xuesong Zhou during that time, a distance of 18.4 million kilometres was travelled by domestic freight in the UK. Every year, businesses in the UK lose $£ 10$ billion per year [2] due to congestion. If HGV usage can be reduced by using more sustainable forms and means to distribute goods to city centres, then this could generate major economic and environmental benefits.

Most air pollution in the UK comes from road transport and residential emissions [3]. In 2014, the EU announced it was taking legal action against the UK; this was due to pollution levels persistently exceeding the safe limit. In $2003,61 \%$ of particulate emissions in London were produced by freight transportation, causing an impact on the health of those working in the city as well as the productivity of the firms located in urban zones [4]. Currently, the main method of freight distribution in the UK is via heavy goods vehicles (HGVs). The annual report from the European Environmental Agency (EEA) claims that HGV pollution costs EU countries $£ 40$ billion per year, making up half of all transport air pollution costs. The EEA also stated that HGVs should be charged with an increased amount in certain European countries due to the higher levels of pollution [5]. The UK Government is funding various projects which are researching the use of gas and dual-fuelled HGVs under the low-carbon truck trail [6]. However, even if HGVs were emission-regulated, the problem of congestion caused by $\mathrm{HGV}$ freight delivery to local businesses and shops still exists in city centres.

As stated by the European Commission [7], the combined effects of congestion, safety, noise and environmental issues are both economic and societal issues. These issues not only reduce efficiency and effectiveness of urban freight logistics but also impact the well-being of society due to the negative effects on health. One way to reduce urban pollution is to introduce low-emission zones (LEZ), which aim to promote cleaner urban centres through the 
use of cleaner vehicles and a reduction in the use of older, highly polluting vehicles [8]. In Europe, a modal shift towards environmentally friendly freight distribution is promoted by the European Commission, governments and local authorities. However, as the financial engineering of the projects is complex, a long period of time will be required before implementing the modal shift [9].

A multimodal system using light rail is an important concept and needs serious considerations. For the case of Newcastle upon Tyne, the interested reader is referred to [10]. It is evident that a modal shift towards more sustainable transport methods is needed. Such a project could generate employment, environmental benefits and business, although large amounts of public and private investments in the infrastructure and construction would be needed in order to implement such a system.

The Tyne and Wear metro service in Newcastle upon Tyne is chosen to act as a case study, outlining the potential for light rail services to become well-adapted and suitable for a complementary freight delivery service. We focus on how the interior of the metro vehicle can be adapted in order to operate as a freight service. Various designs are developed, discussed and analysed along with a thorough review of the safety and security considerations. A full evaluation of the designs is completed, while discussing the levels of investment needed with the benefits and weaknesses of each design.

Autodesk Inventor simulation package is used to develop visual models, demostrating the way the interior of the metro carriage could be adapted without major changes to the existing rolling stock construction. The advantages and disadvantages of such a system are highlighted, conclusions about the effectiveness of this innovative idea are derived and consequently whether this freight system could be practical for the Tyne and Wear metro and other light rail systems.

\section{Current Systems}

A HGV refers to a large goods vehicle; it is the term used by countries within the European Union (EU) for vehicles with a total mass of over three and a half tonnes [11]. HGVs are currently the most common form of freight distribution in the UK. In 2014, road freight was the main method of freight transportation in the UK, with $75 \%$ of goods transported by HGV over rail and water [2]. HGV use peaked in the UK in 2004, before the recession and has been on the steady increase since 2012 [12].

The advantage of using HGVs for transportation of goods is that they can deliver goods directly to the door of the customer, often eliminating the need for intermodal transport. However, there are restrictions related to the use of HGVs in the UK. The maximum vehicle weight in the UK is $44 \mathrm{t}$ (truck, fuel and load) [13]; this governmentenforced law means that freight distributed by HGV often cannot compete with the high volume of goods transported by rail or water. HGVs are generally seen as being environmentally unfriendly and are a major cause of inner city pollution. $\mathrm{HGV}$ transport by road produces $76 \%$ more $\mathrm{CO}_{2}$, $90 \%$ more particulates and up to fifteen times more $\mathrm{NO}_{X}$ than the equivalent journey by rail [14].

Dense inner city zones require smaller logistics vehicles in the modern environment. City freighters are vehicles with a relatively small capacity that can perform distribution activities to locations along narrow and crowed streets in city centres [15]. They are often significantly more environmentally friendly (electric or hydrogen based).

Electric vehicles (EVs) are a cleaner alternative to HGVs which use lithium-ion batteries that can be charged at different locations such as at home or the workplace. The UK Government has offered various benefits to those who use EVs at home or for business such as a grant of up to $20 \%$ of the cost of the vehicle (up to $£ 8000$ ) [16]. This scheme aims to improve the air quality in city centres by reducing the carbon emissions from freight vehicles. Using EVs for freight distribution in city centres also reduces noise pollution due to the near silent state at running speed.

However, the case for solely using EVs for freight and logistics services has its downfalls. More is required to make a feasible business case than just replacing vehicles with electric cars. The current logistics systems in many cities are set up for conventionally powered vehicles. The number of charging points in urban areas would have to be significantly increased to deal with the demand. A new freight network would have to be devised among freight companies, resulting in high initial costs but low operational costs.

Many large cities in the UK, Europe and around the world benefit from light rail transit systems such as metro or tramways. The potential for freight distribution by light rail is a topic that has been researched, though it has not experienced a desirable implementation. Amsterdam City Cargo started running in 2008 following a successful pilot scheme, testing the capability on using the existing tram tracks within the city. City Cargo did not affect passenger tram services as it did not use passenger stops.

For the first phase of testing, the trams travelled without carrying any cargo, to assess the traffic flows along the routes. Delivery points outside the city were used to distribute goods to the corresponding consolidation hubs in the city centre, where small electric vehicles (as shown in Fig. 1) were used to transport the goods to the final destination. Cargo transportation in Amsterdam took 15 min more than direct $\mathrm{HGV}$ transportation; however, this is counterbalanced by the fifteen percent reduction in expenses compared to conventional delivery [17]. 


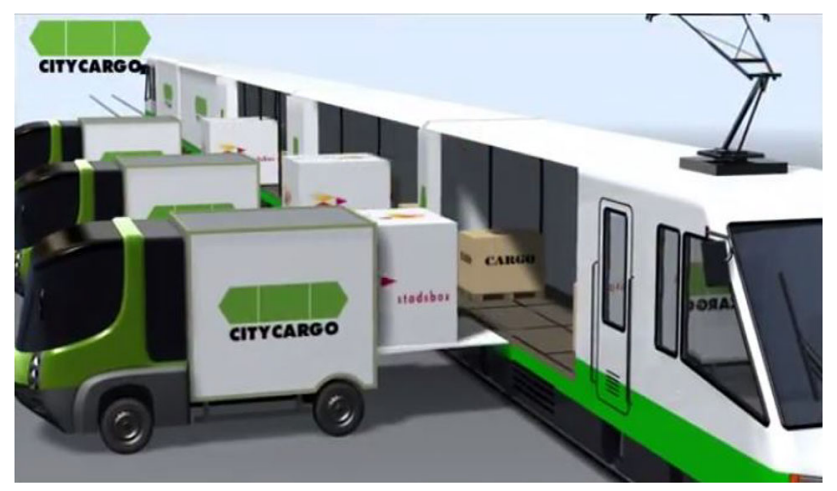

Fig. 1 Amsterdam City Cargo concept

Urban consolidation centres (UCCs) have drawn attention in recent years as a means of promoting existing logistics systems. The appropriate application of a UCC has the ability to improve supply chain performance and reduce societal and environmental impacts of freight transport activity [18].

Automated freight delivery has the potential to be a game changer in the UK logistics industry. Technologies such as radio frequency identification (RFID) and automated guided vehicles (AGVs) are an expanding sector within the freight service market, from which light rail freight systems could largely benefit. Such a fundamental change to the industry could produce benefits and improvements for congestion, emissions and road safety [19].

\section{Current Metro Interior Designs}

Interior designs of metro vehicles are not suitable for the transport of most type of freight, especially not suitable for the transport of hand luggage and passengers' bags. Worldwide light rail and metro systems use various different seating layouts. There are currently two fundamental seat configurations when it comes to metro carriage

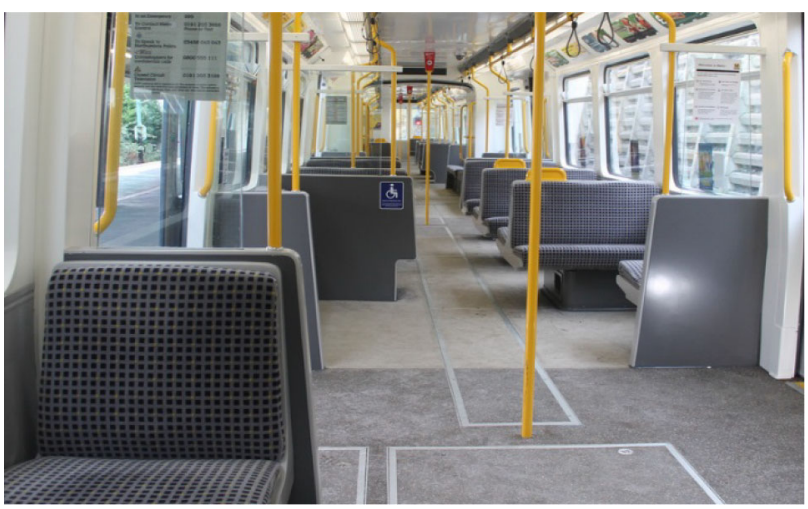

Fig. 2 Tyne and Wear metro interior interiors. The Tyne and Wear metro (as shown in Fig. 2 [20]) uses a transverse (facing) arrangement, which is often used in wider trains. Evidence suggests that passengers prefer sitting in the direction of travel rather than sideways [21]; therefore, this seating arrangement is usually used for services with longer journey times, as the tolerance for discomfort is lower than that in short journeys.

The transverse layout is said to be the least effective at increasing passenger flow on services with multiple stops [21].

This transverse arrangement involves a higher seating density than the alternative of [17] using longitudinal seating, as shown in the London underground (shown in Fig. 3 [22]). Neither layout shows clear potential for freight storage; therefore, alterations would need to be made. The Institute of Transport Research Studies at Monash University conducted a study [23], and researched on how seating arrangements can affect dwell times on metro services. The Stockholm metro was used as a case study, in which the seating arrangement was changed from transverse to longitudinal and tested during an eight-week period. The study found that there was a $2.4 \mathrm{~s}$ reduction in dwell time caused by the new seating arrangement. These marginal gains would accumulate over the service to contribute to a better compliance with the timetable.

Through a review of alternative freight transport methods, large benefits related to switching to an unconventional mode of freight transport such as the reductions in $\mathrm{CO}_{2}$ and particulate emissions could be maximized. HGVs are the most common form of freight transport in the UK today, yet they cause many of the environment problems due to their inefficiency. Certain transport modes are clearly not suitable for some applications; however, combining modes of transport would be a good approach towards the goal of increasing efficiency while reducing emissions within urban centres. Cities are unique and vary from one to another, and thus, one freight system may not be suitable to all urban areas.

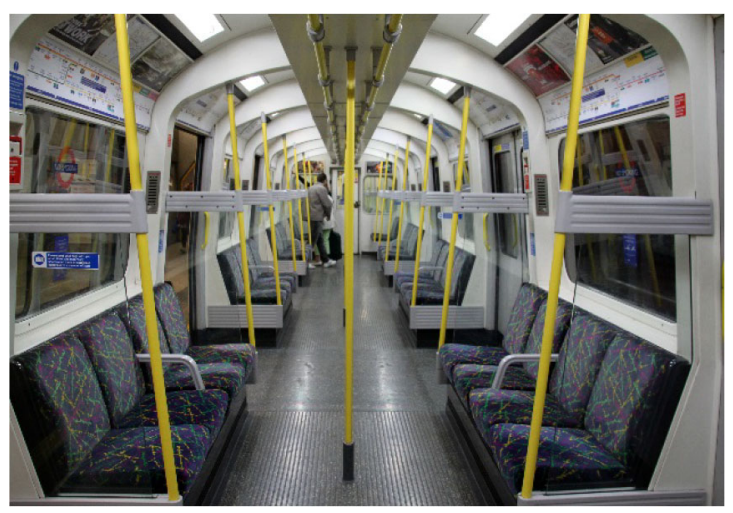

Fig. 3 London underground interior 
According to [10], for the case of Tyne and Wear region, the utilisation of the Tyne and Wear metro service for freight distribution would allow for a greater usage of the light rail network.

\section{Design Software}

Two computer-based packages have been identified for the visualisation of interior designs: SolidWorks and Autodesk Inventor.

SolidWorks is the most common 3D modelling software package used in industry for detailed CAD models of complex components and assemblies. This software has successfully been used for similar design projects previously. However, the software does not provide the same easy user interface as other software packages provide.

The Autodesk Inventor's easy and user-friendly interface makes it a great package for the use of visual models. After reviewing various software packages that could have been used for the project design work, Autodesk Inventor was chosen due to its availability and easy user interface.

\section{Tyne and Wear Metro}

\subsection{Infrastructure}

The Tyne and Wear metro has been in operation since 1980 and is considered to be one of the world's first electric urban railways, alongside London and Glasgow. The light rail system serves over 60 stations, spanning from Newcastle to Sunderland. Since its introduction, the rolling stock interior design has remained largely unchanged.

The service carries 38 million passengers a year, making a vital contribution to the region, socially and economically. Nexus, the owner of Tyne and Wear metro, claims that every pound invested in the metro yields a return of eight pounds [24]. This shows that if a freight service was introduced on the metro, such a scheme would very likely be profitable.

There is a clear potential for the establishment of a metro-based freight system in Newcastle upon Tyne. In order for such a system to operate, a micro-consolidation centre would be developed at Palmersville, near the metro station [10]. All goods from surrounding businesses would be loaded onto the modified metro train. The train would depart from Palmersville metro station and arrive at a track situated between Jesmond and Manors metro stations (as shown in Fig. 4 [25]), currently only used at night to return trains back to the depot. This section of the track is where a distribution centre would be constructed. Goods would be sorted and transported at the final stage of the journey by bicycle couriers or electric vehicles.

\subsection{Rolling Stock}

The Tyne and Wear metro has one of the largest seat numbers per train when compared to other light rail services in Europe. This high number of seats does not reflect the usage statistics of the metro, suggesting that most passengers travel on the metro for a total of $10 \mathrm{~min}$ [26]. This shows that there is potential for removal and reconfigurations of seats within the carriage.

The current metro trains are usually comprised of two carriages, each made up of two cars [25]. Refurbishments took place in 2010 , extending the life of the carriages by 10-15 years before being replaced [27]. The capacity of the carriage is 232 standing and 68 seated passengers [24]. Each carriage has eight doors and a swivel bogie which connects the two cars. The carriage can be split up into three sections (as shown in Fig. 5 [25]). Sections A and C show potential for freight storage without the need to change the interior due to the larger floor space and accessibility to the doors at either side of the carriage. To increase the freight capacity, section $B$ would need to be reconsidered.

\section{Methodology for Improving Existing Design}

Research into current methods of freight distribution in urban centres was considered when developing designs for a metro carriage capable of freight transport. There were three design scenarios to be explored. The first being a design that utilised the current metro interior, requiring very low investment and could work as a short-term option. The second scenario was to design a reconfigurable carriage that would be able to provide freight and passenger services alongside one another, and will possess adaptable seating to free up space within the carriage. The final scenario was to design a fully automated freight system that operated using the metro system. Various designs were considered before the final designs were chosen.

An initial CAD model was produced to obtain an accurate visual aid of the current interior layout; this is shown in Fig. 6. This model acted as a foundation for the development of design work. The designs were developed from initial sketches to 3D CAD models using Autodesk Inventor. These models helped to present the designs in a visual and realistic way, compared to the hand sketches. An evaluation of the final designs was completed using a decision matrix, comparing scenarios against a set criterion. The potential for such a system is discussed and conclusions are made, discussing the benefits and limitations of implementing such a concept. 


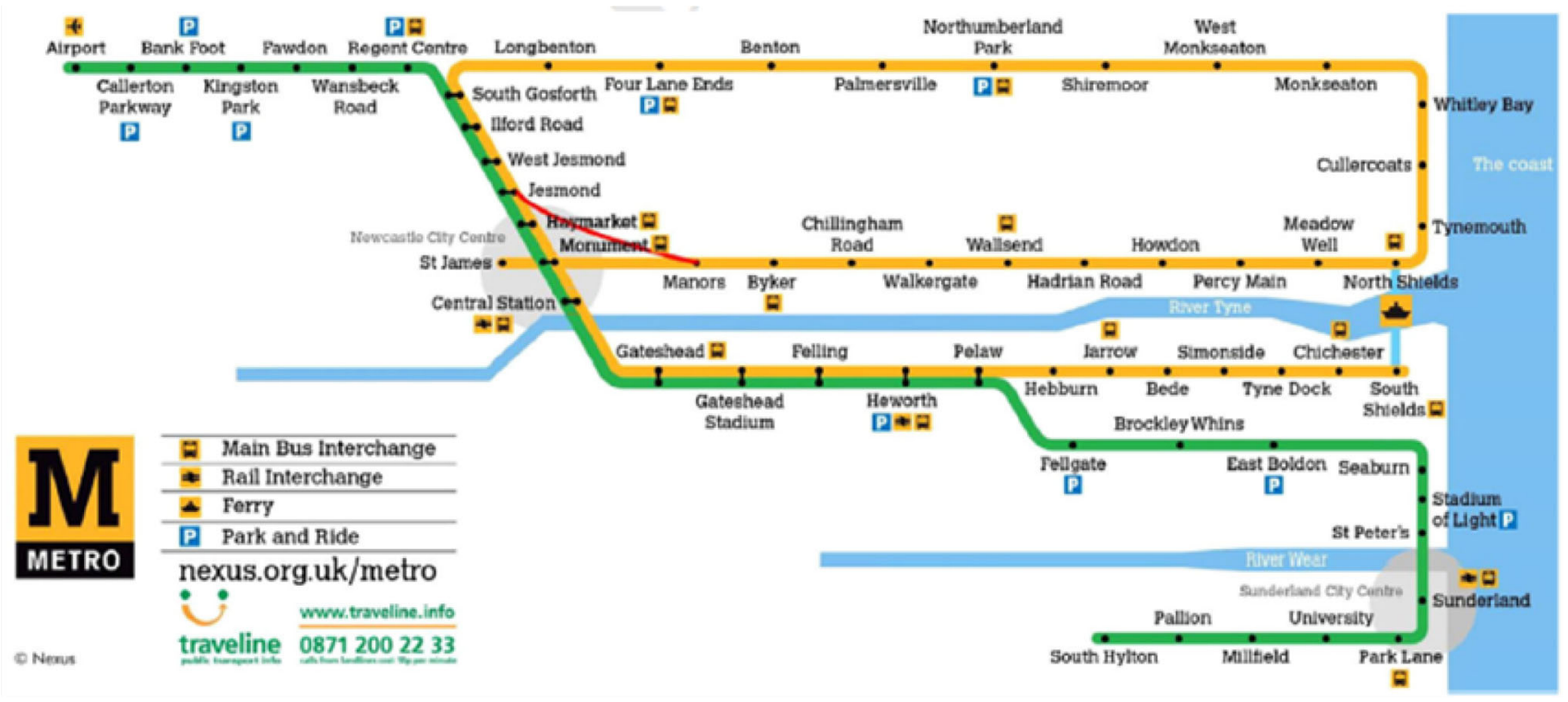

Fig. 4 Metro map, showing the track between Jesmond and Manors

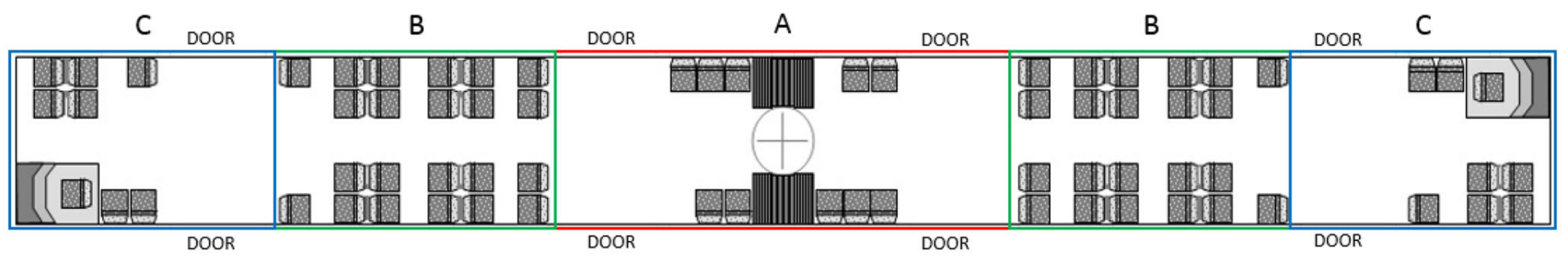

Fig. 5 Current metro configuration, with highlighted areas A, B and C

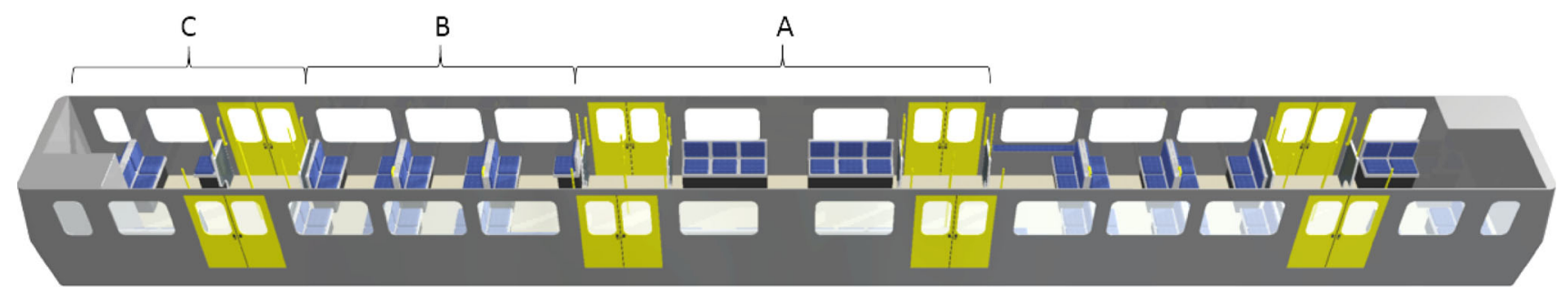

Fig. 6 Autodesk Inventor model of current design

\section{Application}

\subsection{Design 1: Utilising the Existing Design}

Designs 1.1 and 1.2 have been developed using the current metro design and have utilised it for freight storage. These designs would involve the lowest investment due to the minimal amount of changes made to the carriage interior design. As shown in Fig. 7, there is significant space in the doorway and longitudinal seating area (this area is depicted by section ' $A$ ' in Fig. 5). In order to optimise the use of space in this part of the carriage, the production of bespoke cargo boxes would be needed.

\subsubsection{Design 1.1}

Design 1.1 makes efficient use of the open space by using wheeled boxes to transport the goods on and off the carriage. A full depiction of the design in full operation is given in Fig. 8. The boxes would be stored uniformly within the carriage, fitting two boxes side by side in the longitudinal area and three boxes in the door area. The boxes would have to be carefully arranged around the pivoting bogie in the stationary section of the carriage, making sure all four wheels are positioned securely, preventing unsafe movement. The boxes would be locked into position using a footbrake. This method of freight storage on the metro could be applied to a passenger service by 
Fig. 7 Inventor model showing the potential for goods in the middle of the carriage

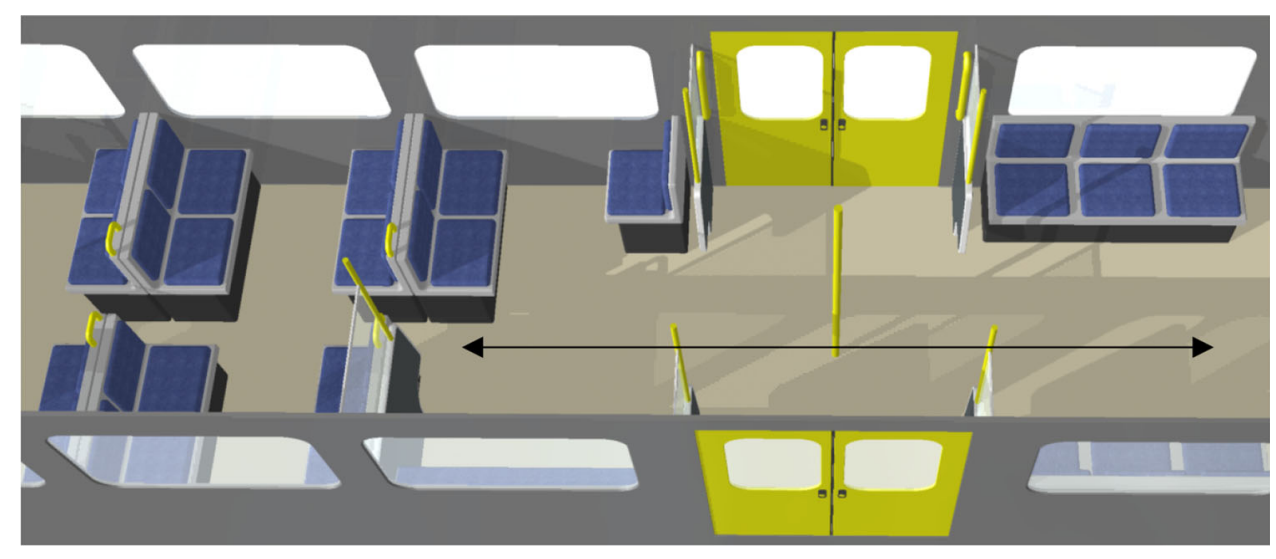

Fig. 8 Display of Design 1.1 when in operation

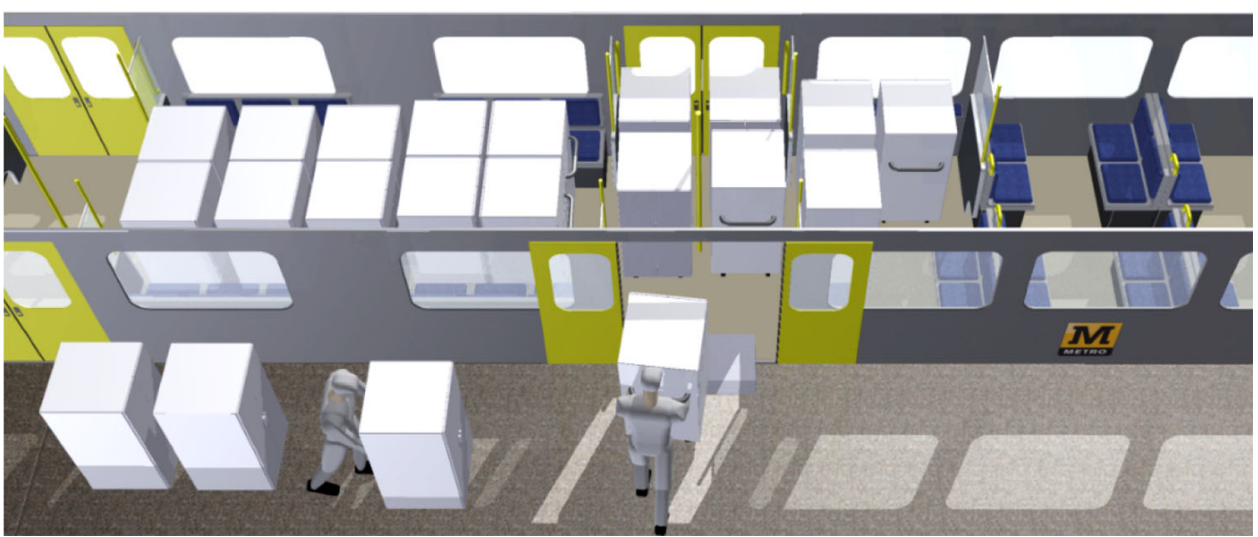

closing off one of the carriages; however, this arises the problem of increased dwell time (the time taken at each station). For this method to be efficient enough to work alongside the passenger service, the boxes would need to be removed from the carriage by workers extremely quickly. This design would work best as a service outside of passenger service hours. In order for the freight service to act alongside the passenger service during the day, the dwell time of loading and unloading cargo would need to be significantly reduced (see Design 3).

\subsubsection{Equipment and Features}

Design 1.1 involves bespoke cargo boxes, specifically dimensioned to fit within the constraints of the current metro. The boxes would have detachable shelving that can be rearranged as needed, to suit different freight sizes. Using shelving allows different goods to be stored in one box while being easily differentiated, acting similar to a bento box [10]. The height of the box is just under that of the average human height, to allow the user to see ahead when manoeuvring the box. The boxes will be mounted with swivel wheels possessing brakes to allow them to be moved onto the metro by hand. This application eliminates the need for forklifts as these would not be able to load the cargo onto the metro effectively.

\subsubsection{Design 1.2}

Design 1.2 (as shown in Fig. 9) also utilises the metro design without modifying the carriage. The transverse seating could be used to accommodate platforms in which freight could be stored above. This design is suited towards smaller freight volumes, as the packages would have to be individually placed in the storage area. A sack truck or lifting trolley could be used to move the goods on and off the carriage. These platforms could simply be made from a sheet of plywood or other rigid material. This design is easily set up and could be very effective for smaller freight volumes at less busy times.

\subsection{Design 2: Reconfigurable Carriage}

Design 2 focuses on modifying the metro design to act as a reconfigurable carriage, allowing the parts of the train to be quickly switched between passenger and freight service. 
Fig. 9 Design 1.2 using platforms over the current seating

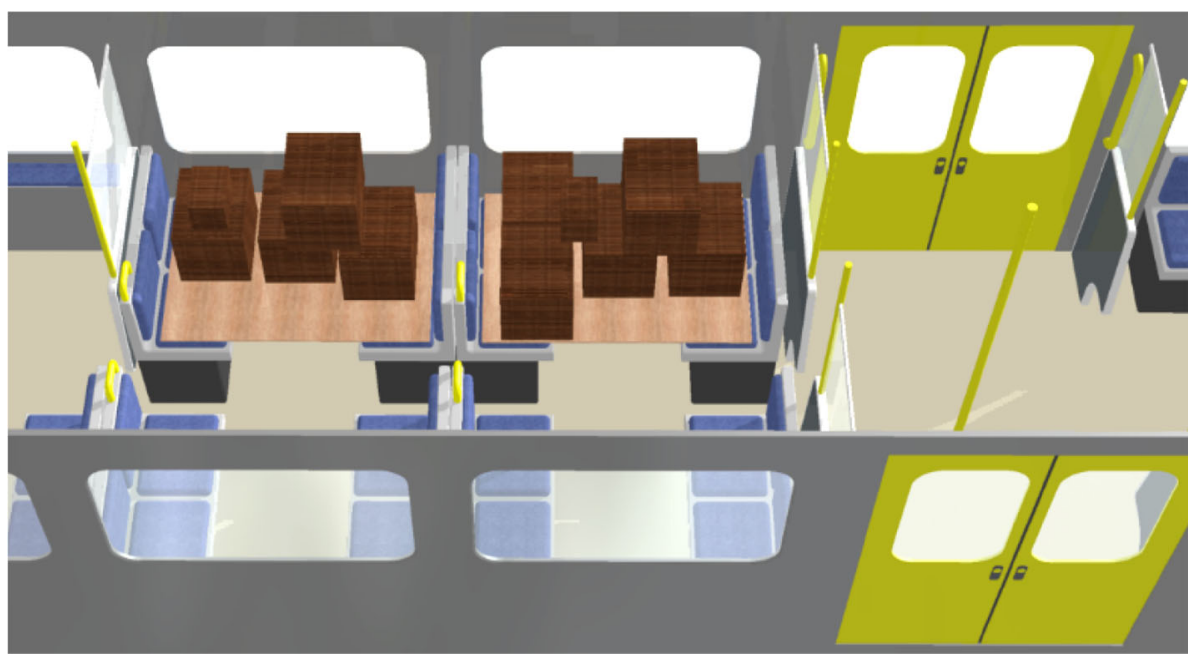

\subsubsection{Design 2.1}

After considering results from the research on rolling stock design by Monash University [21], an alternative design using longitudinal seating along the carriage length was developed. Design 2.1 makes use of the more efficient seating arrangement, creating more floor space for freight storage. Standing space on board the train would be increased; however, this configuration would reduce the number of seats available in the carriage. Due to the average journey time on the Tyne and Wear metro being only $10 \mathrm{~min}$ [26], this arrangement would unlikely affect or increase passenger discomfort. The introduction of foldable seats would make the carriage more adaptable for a quick change between freight and passenger services. This folding seat design drastically increases the space inside the carriage, as shown in Fig. 10.

The panels (as shown in Fig. 11) act as a barrier from the doors, causing a reduction in floor space due to the distance from the side wall (roughly a seats width). To address this problem and create more space, these panels could be made foldable (as shown in Fig. 12) by using a lock and turn mechanism with access via a key. There are limited options to remove the panels completely as they act as a safety barrier from the automatic moving parts that operate the carriage doors.

Removing the central handrail and adding more grab rails at head height increases space without compromising passenger comfort. An addition to the design would be to add portable shelving to the part of the carriage between the doors and pivoting bogie. The shelving would be mounted on wheels with brakes to allow easy entry and removal from the carriage. This shelving would be used for smaller, individual packages that would not be transported using the cargo boxes.

Figure 13 shows the organisation of the shelving and cargo boxes inside the newly designed carriage. The removal of the door panels creates an open plan space in which a larger freight volume can be stored. In order for the freight section of the carriage to be kept separated from the passenger section, barriers would be needed to deter passengers from entering the unauthorised area. Currently, when metro drivers are under instruction, an elasticated sheet is raised by connecting the handrails to section off that part of the carriage. However, this method is only applicable to the areas of the carriage with an abundance of handrails. In the middle section of the carriage, another method would need to be used. Through the research of

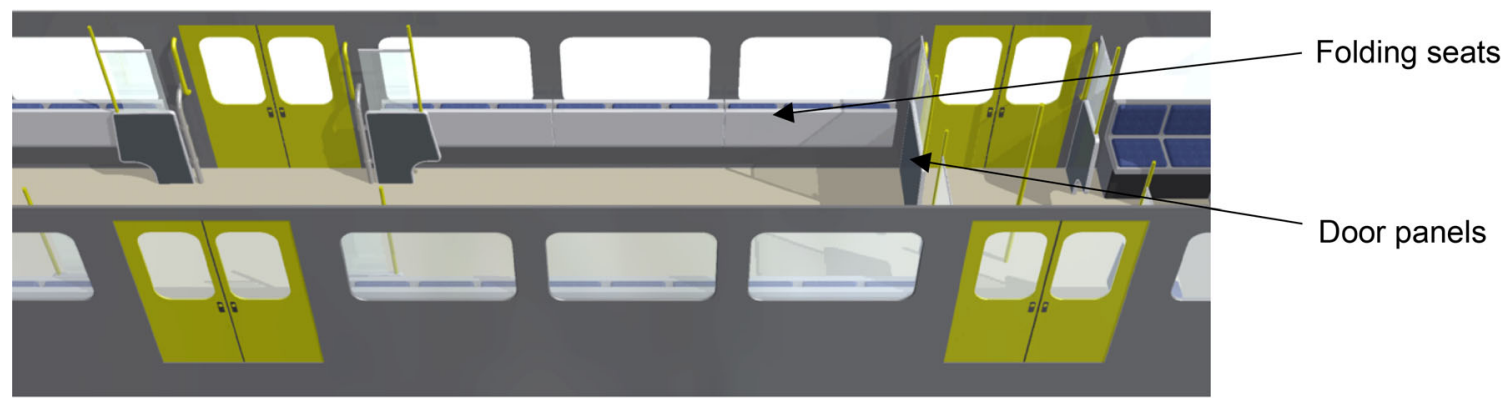

Fig. 10 Folding seat design 
Fig. 11 Folding panel design

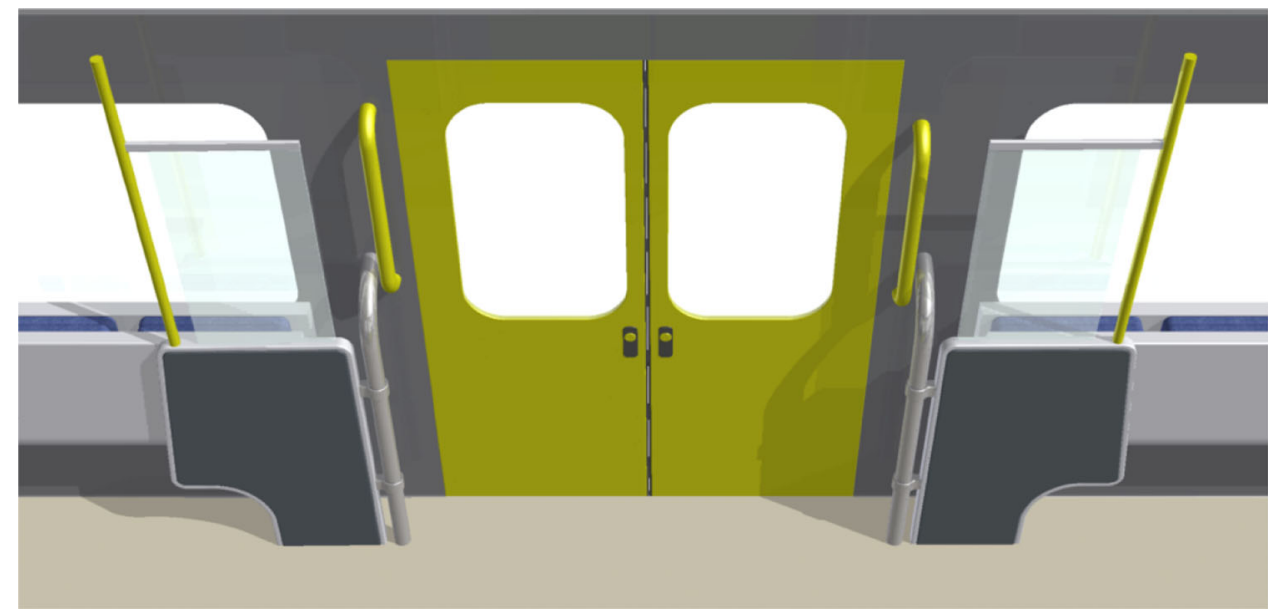

Fig. 12 Door panels

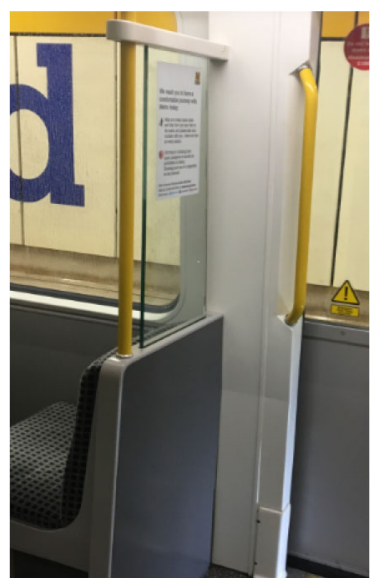

various barrier methods, it was concluded that the best solution would be to use extendable fibre barriers. This method would create a quick and easy way of sealing off one part of the carriage from passengers. These fixtures could be mounted to the carriage wall, eliminating the need to bring any equipment on and off the carriage. Figure 14 shows how these barriers could be fitted to the metro.

\subsubsection{Design 2.2}

Design 2.1 uses an innovative transverse seating design (as shown in Fig. 15), allowing seating to be folded away during freight service. The design uses a central bar in which both parts of the seat are mounted. This support bar is able to rotate around a pivot, connected to the metro wall. This pivot would be locked in and out of place using a simple spring lock mechanism, similar to the mechanism commonly used in gym equipments.

This design would have the same effect on floor space as the longitudinal folding seating arrangement presented in Design 2.1. Using this design would increase the number of seats available in peak times. However, the time taken to fold in all the seats would be longer than that of a simpler longitudinal seating arrangement shown in Fig. 10. Figure 16 shows how the folding design would work when in full operation.

This design would allow the metro to be utilised more effectively during peak times when capacity is much greater than usual, such as after a concert or football match. Therefore, the option of being able to adapt the carriage in this way would positively affect both the freight and passenger services.

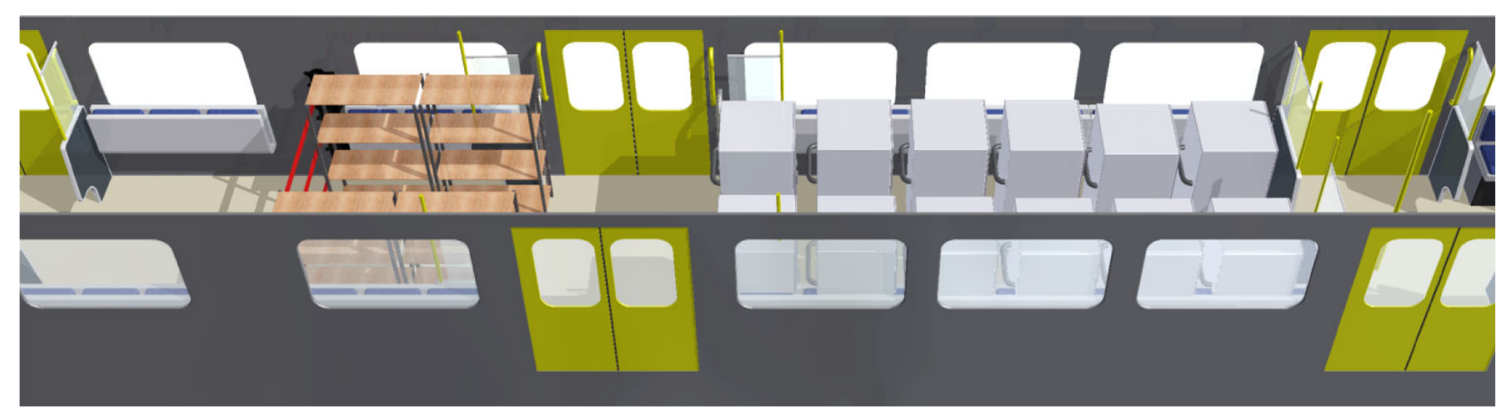

Fig. 13 Model showing the positioning of portable shelving on board the carriage 
Fig. 14 Extendable barriers in the mid-section of the carriage
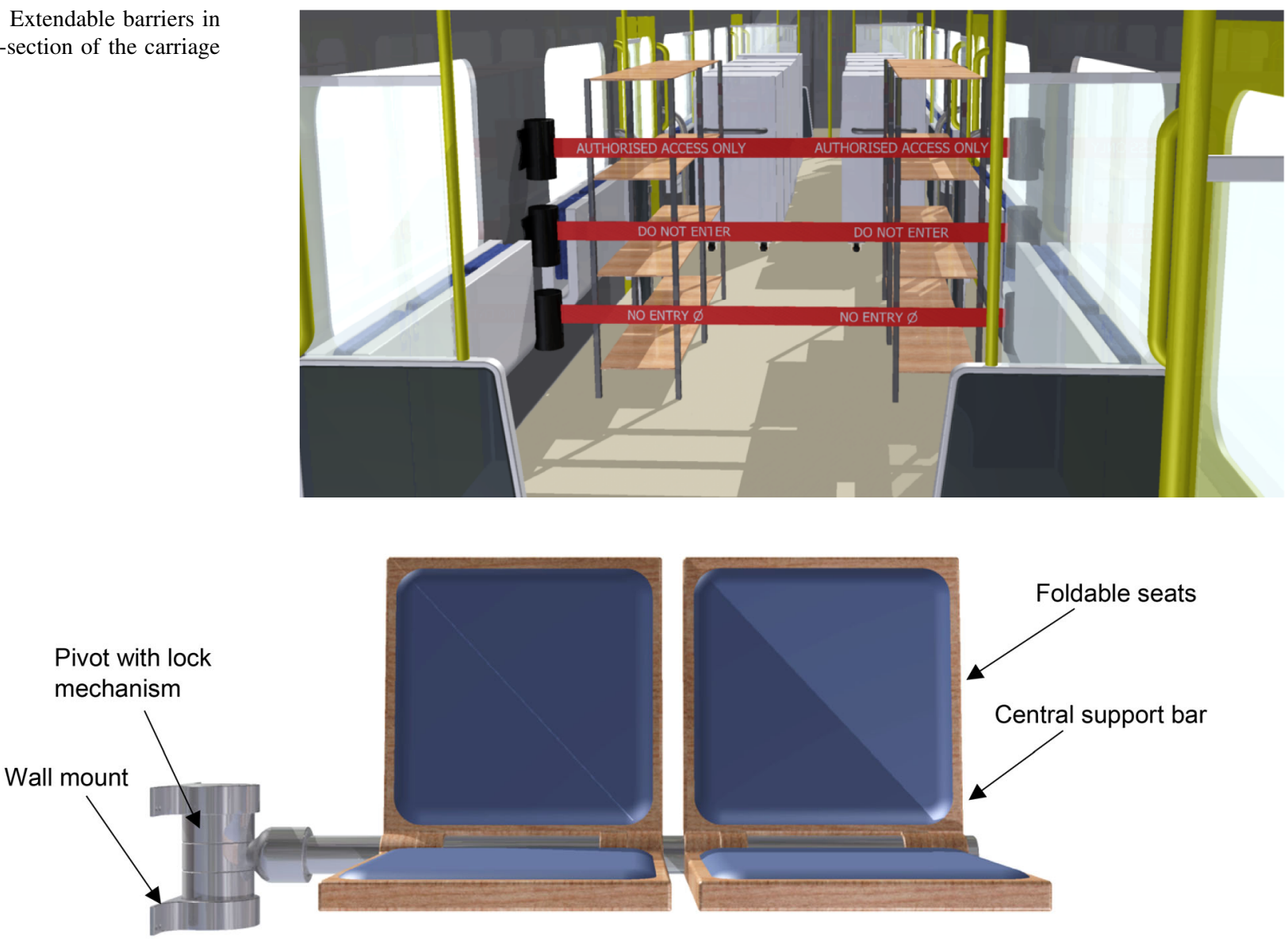

Fig. 15 Transverse folding seat design

Fig. 16 Transverse seat design in operation
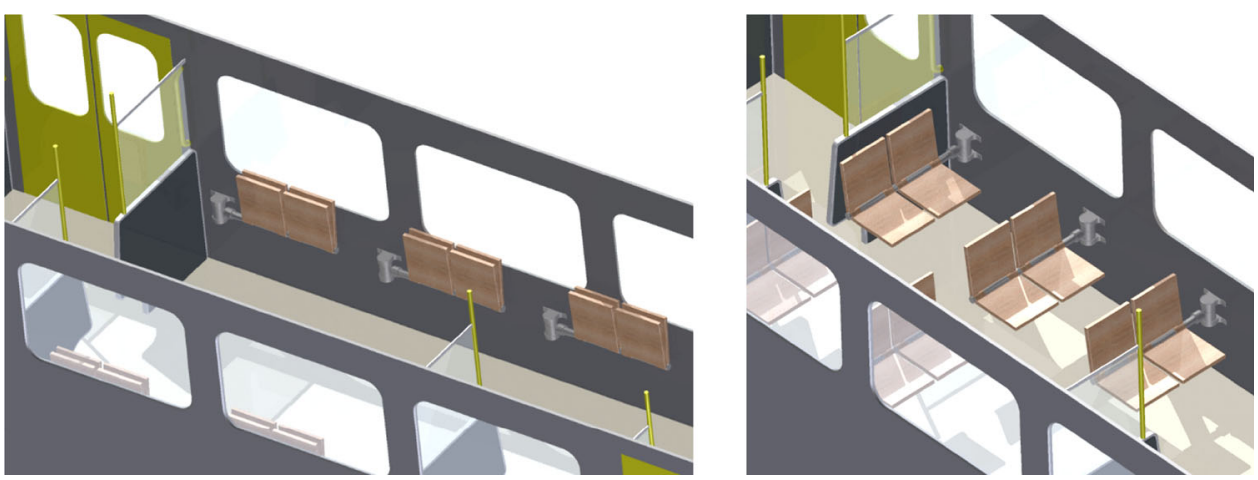

\subsubsection{Design 2.3}

Design 2.3 has been developed from Design 1.2, by creating a horizontal platform in which smaller packages would be stored during low-freight volume periods. The design utilises the longitudinal seats next to the pivoting bogie, by making the seats foldable into a flat platform. Figure 17 shows how the seats would be refitted with a locking mechanism that would allow movement into the horizontal position by simply applying a force to one part of the seat. This mechanism is similar to those used in caravans to convert a sofa into a bed [28].

When the seat is in the horizontal position, smaller packages could be stored above the surface. The position of the mechanism at the side of the seat eliminates the need to modify the electric components underneath the seat. This design allows for easy configuration between passenger and freight service. However, this design would not operate with the same freight volume as Design 2.1 or Design 2.1, 
Fig. 17 Folding seat mechanism diagram

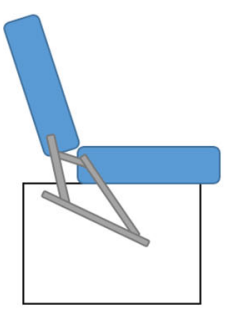

and therefore, it would be more applicable to a quieter service.

\subsubsection{Motored Seating Concept}

$\mathrm{B} / \mathrm{E}$ Aerospace [29] is a company that designs interiors and utility systems for commercial aircraft. The company has designed a seat that would adjust for taller passengers via small motors mounted in the floor. The design arose to address the problem of passenger discomfort on board long flights [30]. The movement of the seats would be controlled by the staff on board the plane via a single control unit (see Fig. 18 [29]). Mechanically controlled seating is a concept that could be applied to a metro car. This seating design would allow quick and easy movement of seats when positioned in a transverse seating layout. However, this design could be said to be overengineered and inapplicable to the metro, as the complexity of the electronics needed would require a full redesign of the metro rolling stock.

\subsection{Design 3: Full Automation}

Design 3 focuses on the use of automation within the carriage. The concept includes the use of autonomous guided vehicles (AGVs) to distribute the freight from the consolidation centre directly to the customer. Full automation means that the vehicle would be capable of safely completing full journeys without the need for an operator, while encountering normal traffic and weather conditions. This method would involve a high level of private and public investment to become fully integrated

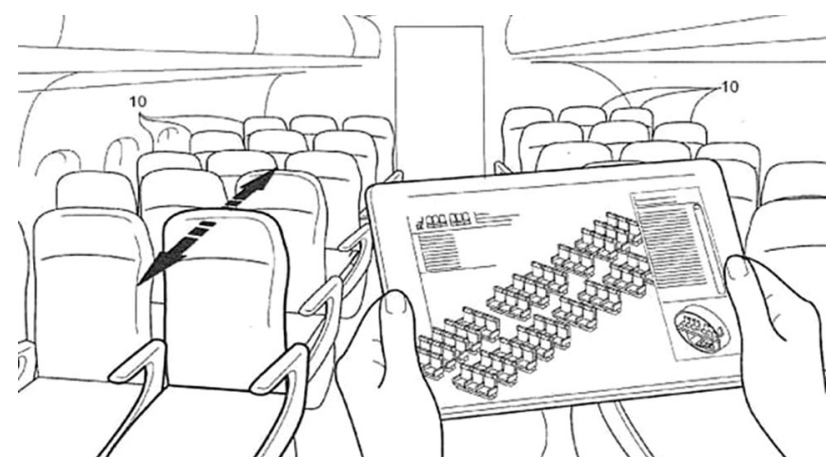

Fig. 18 Motored seating concept on board a commercial aircraft

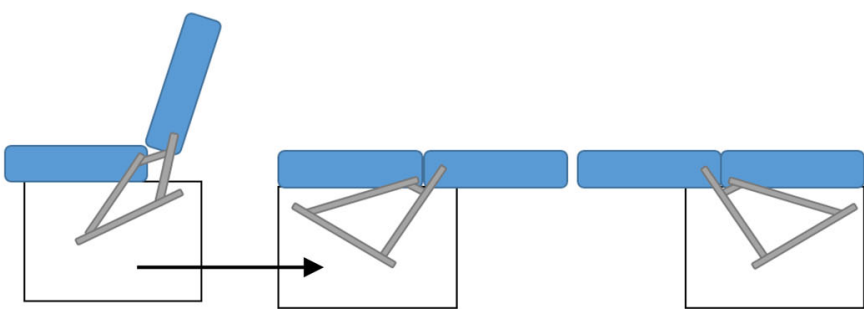

into the system, but it could be the most efficient and effective way to distribute freight in the long run.

\subsubsection{Automated Guided Vehicle (AGV)}

The AGV would act as the cargo container, distributing the goods directly to the customer. AGVs are commonly used in modern warehouses, making use of systems such as radio frequency identification (RFID) [31]. AGVs can help reduce product damage, eliminate lost loads and simplify equipment maintenance in warehouses [32]. The use of AGVs can deliver year after year cost reductions. Figure 19 [32] shows various applications of AGVs for moving goods.

7.3.1.1 Radio Frequency Identification (RFID) RFID utilises radios waves to identify goods by using chips [31]. Electromagnetic fields are used to identify and track chips attached to the goods. The RFID device serves a similar purpose to that of a bar code or magnetic strip on a credit card [33]. Active chips have a local power source such as a battery and can operate far away from the RFID reader. RFID has many applications such as access management, tracking goods and airport baggage logistics.

Using RFID in an automated system on the metro would benefit the operational efficiency of the system by eliminating the need to check the goods manually. An RFID reader could simply be mounted on the carriage door, which would monitor the inward and outward flow of goods on the metro. A computer would store this information, allowing all freight to be tracked effectively.

7.3.1.2 Navigation In order for the AGV to navigate to the correct destination, an advanced navigation system would need to be applied to the system. Visual guidance would allow AGVs to operate by using cameras to record features along the route. Specially designed stereo cameras with 360 degree images would be used to build up a 3D map, allowing the AGV to follow the route without human assistance. However, geo-guidance are considered to be a more accurate method of navigation. A geo-guided AGV would recognise its environment to establish its position. Obstacles would be detected and identified, allowing the AGV to avoid obstructions. 
Fig. 19 Automated guided vehicle applications
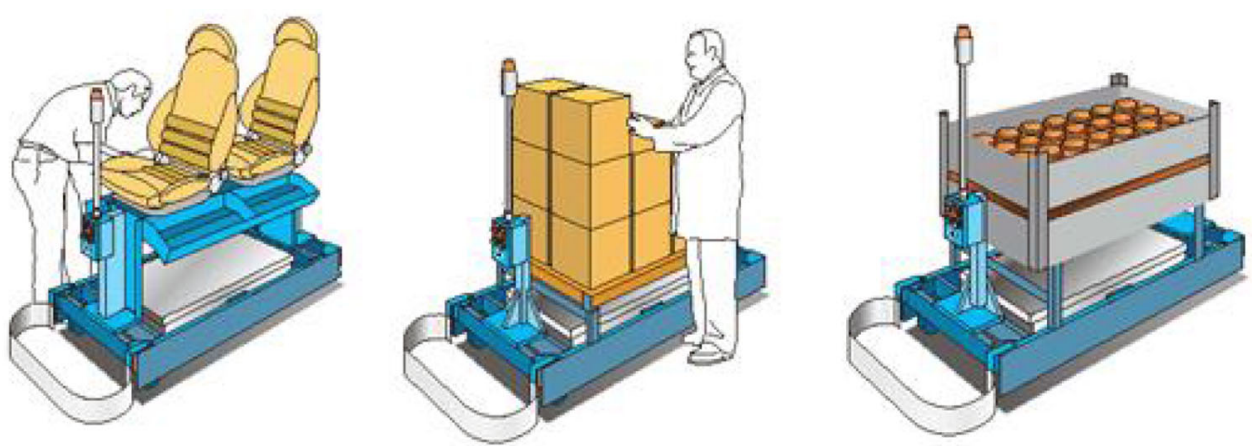

7.3.1.3 The Metro AGV The metro AGV would operate using geo-guidance navigation technology and would be powered by a lithium-ion battery, located underneath the goods in order to lower the centre of gravity. Lowering the centre of gravity of the AGV is a key to inclined transit, helping to prevent the AGV from tipping over. The AGV would travel at average walking speed $(1.4 \mathrm{~m} / \mathrm{s})$ [34] in busy pedestrian areas, with the ability to speed up in open areas. The AGV would be stored at the unused area at the end of the metro platform, before positioning itself in front of the yellow line at the end of the platform specifically reserved and cornered off for freight use. The AGV would have automated sliding doors at either end allowing easy access to the goods inside. Figure 20 shows the Inventor model of the AGV design and outlines the main features. The AGV would be roughly $1 \mathrm{~m}$ wide, $1.5 \mathrm{~m}$ long and $1 \mathrm{~m}$ tall. These dimensions would allow two AGVs to fit side by side within the modified metro carriage with sufficient room to walk in between. A key feature of the AGV is the double wheel. The double wheel allows the AGV to turn at very sharp or tight corners without wearing down the rubber tyres. The double wheel would simply rotate around 90 degrees and the AGV would move in the perpendicular direction. This feature allows the AGV to move within the carriage and along the platform with ease.

For the purpose of this design, the interior design of the carriage has been extended or carried forward from Design 2.1. The AGVs would have the ability to arrange themselves within the carriage during transit; this would allow the correct load to be by the exit door when it arrives at its destination and needs to leave the train. To do this, one space would need to be kept free at all time to allow the AGVs to move in a way similar to a block puzzle (see Fig. 21). This feature greatly improves the efficiency of the freight service, reducing dwell time at each station. The current dwell time at metro stations is roughly $20 \mathrm{~s}$; this
Fig. 20 Metro automatic guided vehicle

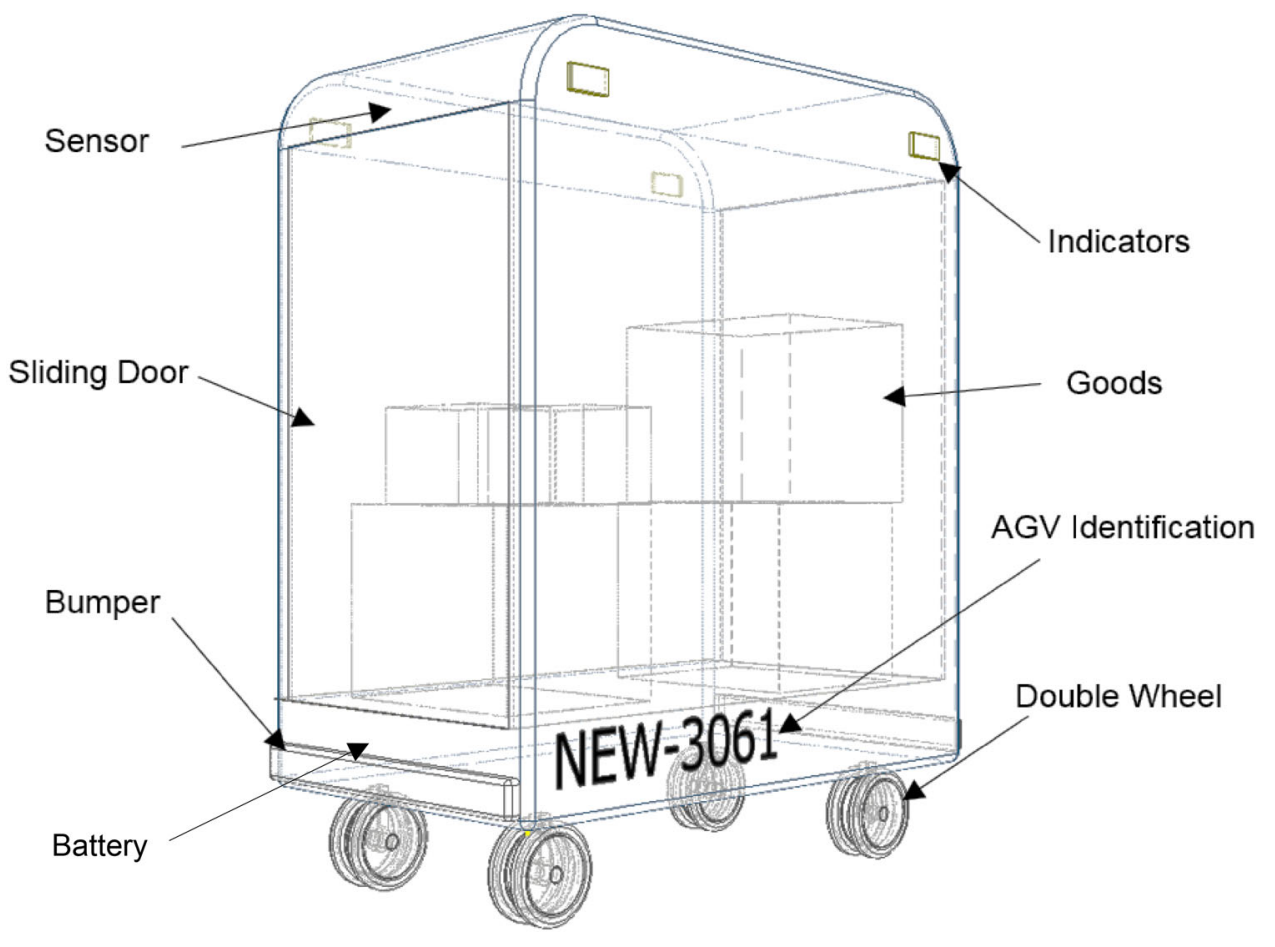


Fig. 21 Plan view of AGVs on metro

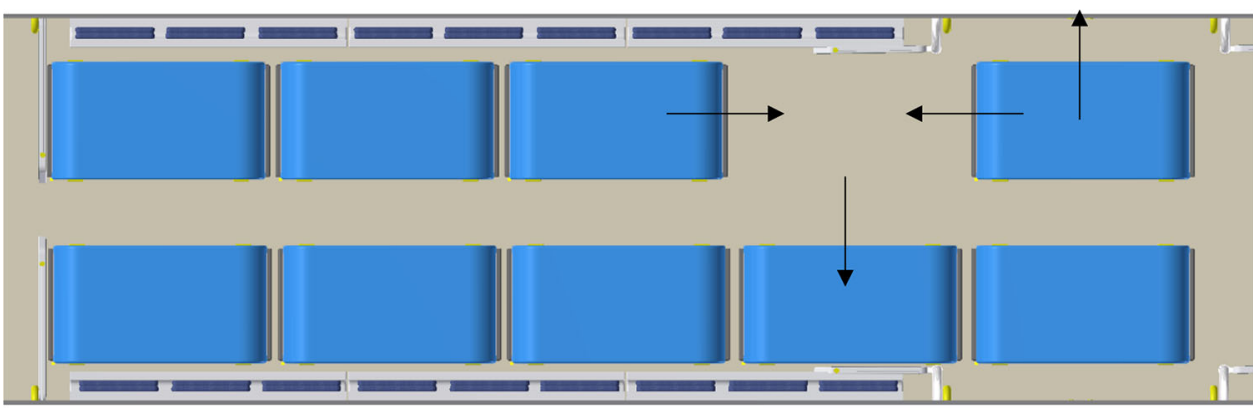

time would allow two or three AGVs to leave or board the train.

Figure 22 shows an Inventor model of the AGVs in full operation on the metro, displaying how the AGVs could position themselves on the station platform, ready to enter and leave the carriage as the doors are opened.

\subsubsection{Greggs: Four Lane Ends Case Study}

Greggs PLC is a Newcastle-based company, operating with 29 outlets in Newcastle, 9 of which are located in the city centre. In 2011, Greggs opened a new $£ 16.5$ million site in Longbenton [35], 4.5 miles from Newcastle city centre. The site is located one mile from Four Lane Ends metro station; this shows that there is large potential for a metrobased delivery system to supply its outlets in the city centre. Figures 23 and 24 show the location of the Greggs manufacturing site in relation to Newcastle city centre and Four Lane Ends metro station.

The route from Greggs in Benton to the metro station consists of predominantly wide, open pedestrian areas and cycle lanes, making it an ideal environment for the use of AGVs. The Greggs site would be able to load AGVs with bakery goods, which would be taken on the metro to the city centre outlets, many of which are located next to metro stations. The potential for such a system is large, with many positive economic and environmental impacts that could incur. The AGV would be modified to take long trays

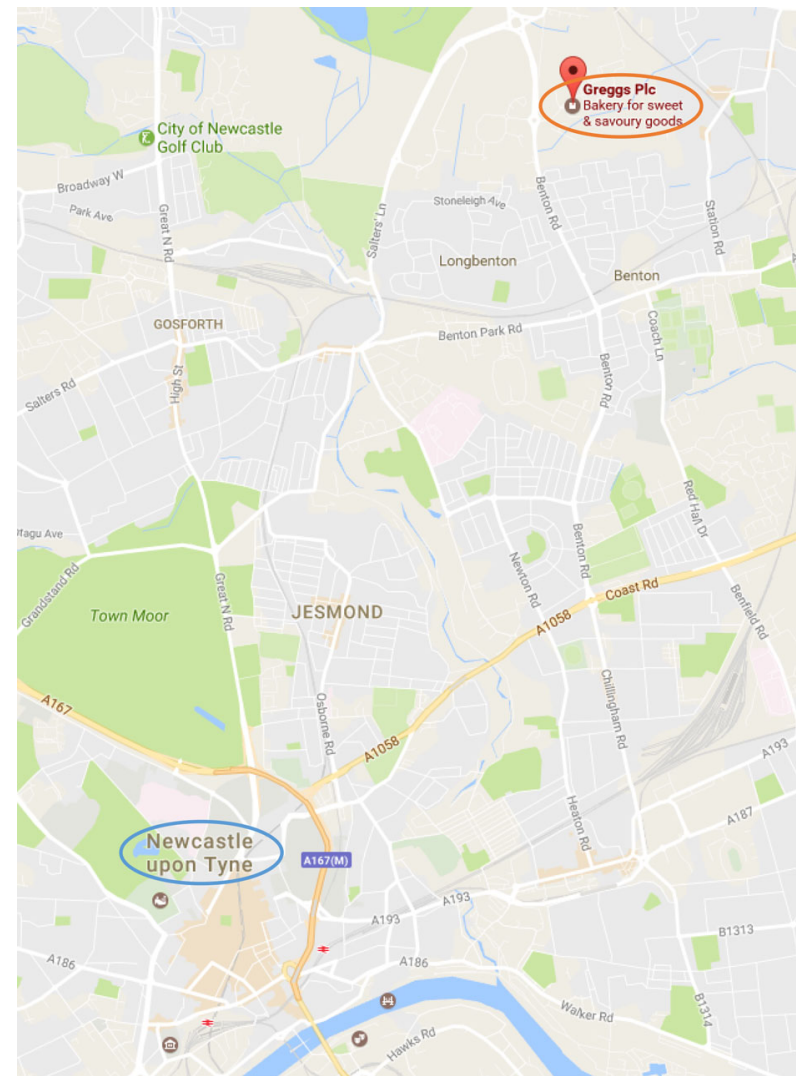

Fig. 23 Map showing location of Greggs PLC
Fig. 22 Metro AGVs in full operation

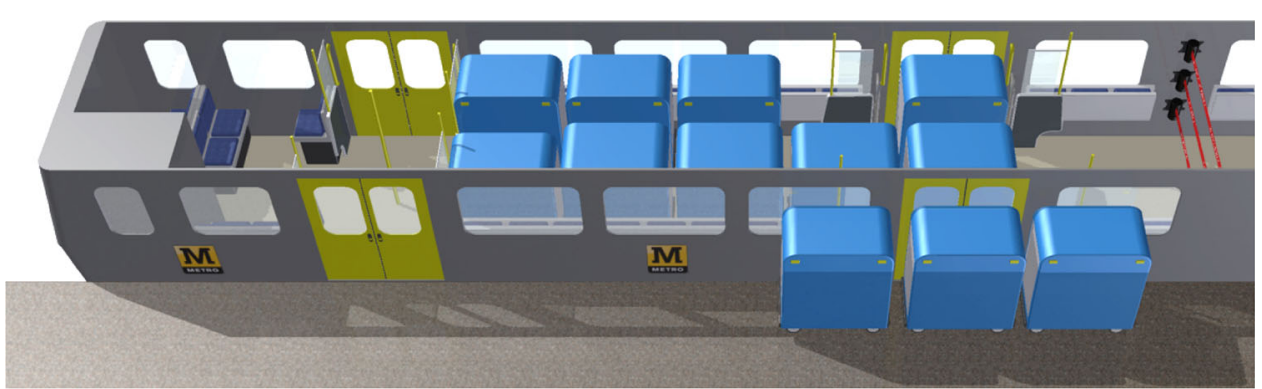




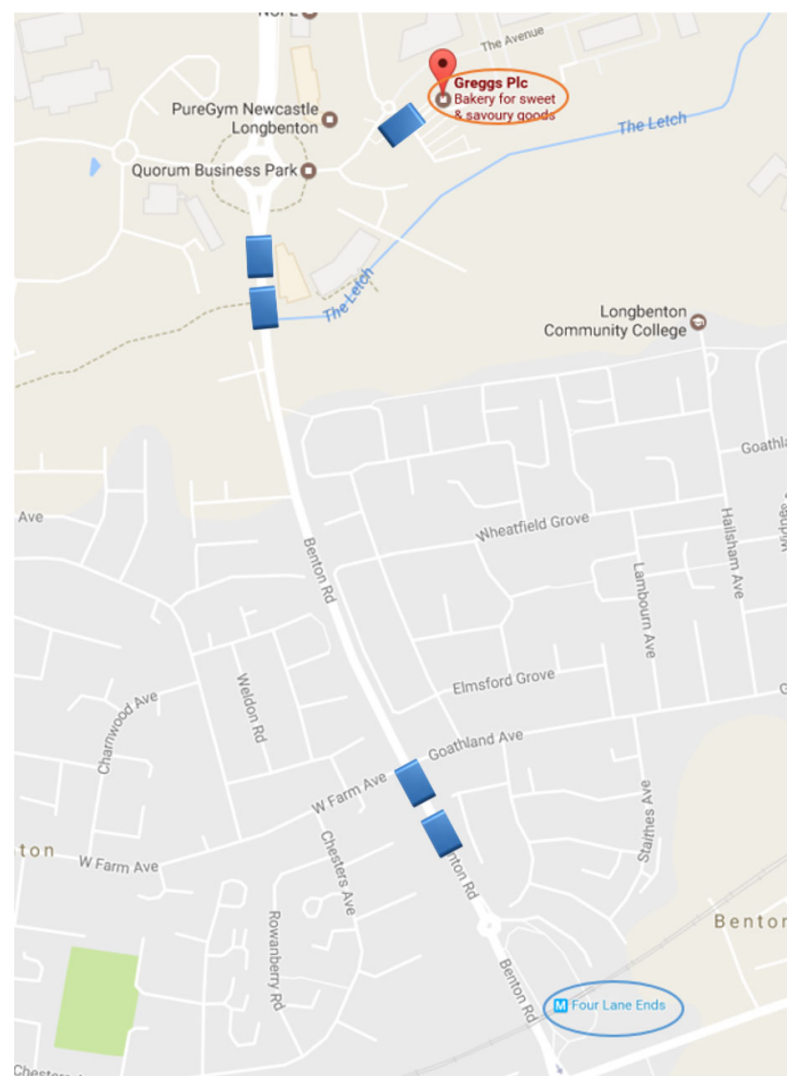

Fig. 24 Map showing location of Four Lane Ends metro station

of goods that could simply be slotted in and out of the vehicle due to its ideal dimensions.

\subsubsection{Potential for Mainline Application}

The AGV system has potential for application on mainline train systems as well as light rail systems. New developments in rail such as the HS2 line could be adapted for national AGV freight transport, although the freight volume per train might not meet national demands. A problem that arises is that the train is not levelled with the platform in mainline services, unlike light rail services. This would cause a problem for the AGVs entering the carriage. An automatic ramp could be mounted to the train, allowing easy access for the AGVs. Automatic freight services are unlikely to be introduced on mainline services before light rail services due to the increased logistical complexity and investment needed, although it is a point of discussion for governments in the future.

\subsubsection{Safety and Security Measures}

In order for the AGVs to be safe and secure, various design features need to be addressed. The AGV would have an obstacle sensor at the front and rear of the vehicle to detect obstacles such as pedestrians, preventing unwanted contact. Two areas will be demarcated in front of the AGV: the first distance being a warning area and the second being an emergency area. If an object is in the emergency area then the AGV will stop immediately. All AGVs will be equipped with flashing lights and sounds as to warn people if the AGV is too near. The AGV will only be accessible to the receiver of the goods via an access card or code, preventing any unauthorised access.

Regulations for the development and use of autonomous vehicles are yet to be confirmed by global regulatory boards, and the potential legal issues surrounding autonomous vehicles are undefined [36]. Issues such as assessing liability in the results of accidents involving AGV need to be discussed. The majority of new vehicles in Europe are subject to an approval process and requires that standards are met [19]. However, specialist vehicles intended for limited road use are exempt from this regulatory process, for example, forklift trucks, airport baggage hauling vehicles. The metro AGV would be likely to be exempt to this process due to the nature of its operation.

\section{Evaluation}

\subsection{Methods for Evaluating Designs}

In order to evaluate the designs and propose the final solution, two evaluation methods were completed. A decision matrix uses specified criteria in which the designs are compared and scored against each other, allowing the designs to be ranked from highest to lowest scoring. The designs in this study have been evaluated against a set of key design criteria. The main criterion was system performance as freight storage within the carriage is a vital part of the design. The level of investment needed was another key criterion for the final design; this was an important factor contributing to the overall success of the project proposal. Feasibility, safety, security and versatility are other criteria in which the designs were compared against. For this evaluation, the three key design scenarios were considered as a whole. Design 1 involved utilising the current metro, Design 2 introduced the concept of a reconfigurable carriage and Design 3 developed the idea of fully automated freight system. Another evaluation method is to compare the proposed design to existing freight systems. This comparison would provide a clear comparison of the performance of alternative freight distribution methods. 
Table 1 Design decision matrix

Table 2 Comparison of Design 2.1 to existing systems

\begin{tabular}{|c|c|c|c|c|c|c|c|}
\hline \multirow[t]{2}{*}{ Criteria } & \multirow[t]{2}{*}{ Weight (\%) } & \multicolumn{2}{|l|}{ Design 1} & \multicolumn{2}{|l|}{ Design 2} & \multicolumn{2}{|l|}{ Design 3} \\
\hline & & Rating/5 & Score & Rating/5 & Score & Rating/5 & Score \\
\hline Performance & 20 & 2.5 & 0.5 & 4 & 0.8 & 5 & 1 \\
\hline Cost/investment & 18 & 5 & 0.9 & 4 & 0.72 & 2 & 0.36 \\
\hline Feasibility & 15 & 5 & 0.75 & 4 & 0.6 & 3.5 & 0.525 \\
\hline Ease of implementation & 15 & 5 & 0.75 & 4 & 0.6 & 2 & 0.3 \\
\hline Safety & 10 & 3.5 & 0.35 & 4 & 0.4 & 4 & 0.4 \\
\hline Security & 8 & 3 & 0.24 & 5 & 0.4 & 4.5 & 0.36 \\
\hline Versatility & 8 & 3.5 & 0.28 & 5 & 0.4 & 5 & 0.4 \\
\hline User-friendly & 6 & 4 & 0.24 & 5 & 0.3 & 4 & 0.24 \\
\hline Total weighted score & & - & 4.01 & - & 4.22 & - & 3.585 \\
\hline Rank & & 2 & & 1 & & 3 & \\
\hline
\end{tabular}

\begin{tabular}{lccllcc}
\hline Criteria & Weight & City Cargo [17] & HGVs [11] & $\begin{array}{l}\text { Baseline } \\
\text { Design 2.1 }\end{array}$ & EV [37] & Monoprix [38] \\
\hline Capacity & 4 & 0 & -4 & 0 & -4 & 0 \\
Environment & 3 & 0 & -3 & 0 & 0 & 0 \\
Versatility & 2 & -2 & +2 & 0 & +2 & -2 \\
Congestion & 1 & 0 & -1 & 0 & -1 & 0 \\
Total & 10 & -2 & -6 & 0 & -3 & -2 \\
\hline
\end{tabular}

\subsubsection{Decision Matrix Results}

The design evaluation can be summarised in the form of a decision matrix as shown in Table 1. Design 2 scored overall the highest as it would provide the best solution in the short and medium term. The reconfigurable carriage design scores highly in many of the given criterion, making it the most suitable design for final proposal. The design utilises the space within the carriage by making simple yet very effective changes, allowing for a large increase in the floor space without compromising the passenger comfort. Other benefits are also created by this design, such as the increase in passenger capacity on the train and a reduction in dwell times [21], thus benefitting both the passenger and freight services. With regard to performance, though, Design 2 did not score the highest. Design 3 using full automation scored the highest as this would provide the fastest and most efficient freight solution. Design 1 scored the highest in terms of ease of implementation with the current metro as no changes would need to be made to the carriage itself, but failed to score highly with regard to performance as the freight volume would not be as high as other designs.

As for long-term investment, Design 3 may be the best option. Design 3 shows great potential for future considerations, but this table highlights the weak points in the design, mainly being the high initial investment costs and implementation planning. For Design 3 to be successfully implemented into the Tyne and Wear metro network, further considerations would need to be made to make the scheme more compliant with the current service. This makes this design a long-term choice, as it would not be a viable solution in the short term.

\subsubsection{Comparison of System Performance with Existing Systems}

In order to further evaluate the proposed design, a comparison to existing freight systems has been completed. Design 2, specifically Design 2.1, has been chosen as the proposed design for comparison as this design scored the highest using a decision matrix (see Table 1). The comparison table is given in Table 2.

Each system was compared to Design 2.1 using the criteria as given in Table 2. Capacity of the service was a key criterion, in which no other service scored higher than Design 2.1. The comparison shows that the new design provides similar performance to the already successful Monoprix scheme. The capacity of Cargo Tram and Monoprix services would be similar to that of the reconfigurable metro carriage. HGVs were proved to be more harmful to the environment than other methods of transport [14], causing a negative score in the comparison table. In terms of versatility, heavy goods vehicles (HGVs) and electric vehicles (EVs) scored higher due to their ability to access more destinations than the metro, which is restricted 
to the metro stations. However, the metro could be seen to be more versatile in the sense that it can shift between freight and passenger services easily. The table shows that all other systems have a negative score, showing that they do not theoretically perform as well as Design 2.1 overall.

\section{Conclusion}

This paper has presented solutions for the design work needed to implement a metro freight system in the future. Conclusions about the possibility of such a system being carried out are discussed in this section.

There are many challenges that need to be considered in order to achieve a functional freight service operating on the Tyne and Wear metro. This paper outlined the potential for a freight service on board the metro, without the need for large changes to existing infrastructure or redevelopment of the network.

In order to validate the designs, it must be confirmed that the metro would be able to withstand the extra weight added by the freight packages. The metro trains are designed to withstand a capacity of six passengers standing per square metre. The heaviest equipment on board the carriage would be the loaded AGVs. An AGV would take up $1.08 \mathrm{~m}^{2}$ of floor space when on board the metro and would be the equivalent of just over six people. Six people weighing $80 \mathrm{~kg}$ would be a mass of $480 \mathrm{~kg}$ per square metre. Therefore, the AGV with freight would be able to represent up to $500 \mathrm{~kg}$ in weight, assuming that the majority of the space on board is taken up with AGVs. However, due to the nature of the AGVs on board the carriage, not all space will be taken up (see Fig. 23). It can therefore be said that the axle loading caused by the additional freight in the carriage is acceptable. However, this would need to be confirmed by completing engineering analysis on the existing and new rolling stock.

There were three potential design scenarios researched in this study. The first being a design which utilised the current metro design by using bespoke cargo boxes in the open region of the carriage. This space provided enough room for freight equipments without the need to redesign the internal layout of the carriage. Design 1.2 shows how plywood sheet could be used as a temporary arrangement, providing a platform for freight storage. Through evaluation, it was clear that this method would not provide the same freight capacity as other designs; however, this method could be used as a pilot scheme in the short term by Nexus, to identify whether such a scheme is viable for further investment.

The second design scenario presented a very versatile design in the form of a configurable carriage concept, allowing the internal design to be used for freight and passenger service with quick changes. Three designs were proposed for this scenario, in which Design 2.1 was selected as the highest performing design. This was due to the space that was made available by using the foldable, longitudinal seating. This design acts as the final recommendation due to its advantages in many areas with only minor changes to the carriage interior. Design 2.2 provided an alternative folding seat design, allowing transverse seating arrangements to be folded away to the side of the carriage. Both these designs created large amounts of space in the centre of the carriage. This addition of space would benefit the passenger service by allowing the seats to be folded away during extremely busy times such as after a concert or football game. Design 2.1 proved to be the best solution for this scenario as the longitudinal seating arrangement was more desirable for an interior layout due to the reduction in dwell time in peak hours and increase in standing passenger capacity.

The final scenario looked into the suggestion of using an automated freight delivery service, coinciding with the metro passenger service. This design scenario developed a concept for an automated guided vehicle (AGV) to pick up, transport and deliver the goods to the customer via the metro system. This solution shows promise for a future system, but many changes would need to be made to local infrastructure to accommodate the system. Large private and public investments would be needed to get such a project off the ground.

There is clear evidence to suggest that there is potential for a freight service on board the Tyne and Wear metro. The suggestions presented in this paper successfully provide a realistic and achievable solution to urban freight problems, which can be further investigated in the future.

\section{Future Work}

In order to provide a more detailed proposal, a cost-benefit analysis would need to be completed to show the funding needed to implement a metro freight service. Further analysis into the detail of the designs would need to be completed, such as a study into the components and materials. Engineering analysis into the effects of the increase in load on the rolling stock would need to be made in order to validate any technical uncertainties in the design. This paper briefly discussed how the freight would be stored at the end of the platforms, utilising the unused space; however, more research and design work would need to be completed with regard to the storage and distribution of the freight within stations. The lifts in the underground stations in the centre of Newcastle upon Tyne would need to be adapted to withstand the new demand of the freight network. An investigation into the potential for 
freight storage services at individual stations should be conducted in the near future.

Acknowledgements The authors acknowledge the contribution of Michael Bell, for providing in depth opinions with regard to an automated system throughout the duration of the study.

Open Access This article is distributed under the terms of the Creative Commons Attribution 4.0 International License (http://crea tivecommons.org/licenses/by/4.0/), which permits unrestricted use, distribution, and reproduction in any medium, provided you give appropriate credit to the original author(s) and the source, provide a link to the Creative Commons license, and indicate if changes were made.

\section{References}

1. Independent Transport Commision: Improving the Efficiency of Freight Movements: the Contribution to UK Economic Growth. London (2014)

2. Department for Transport: Domestic Road Freight Statistics, United Kingdom 2015, UK (2016)

3. BBC News: UK Pollution, how bad is it? (2014) (online Blog). http://www.bbc.co.uk/news/uk-26851399. Accessed 13 Feb 2017

4. Crainic, T.G., Ricciardi, N., Storchi, G.: Models for Evaluating and Planning City Logistics Systems. CIRRELT (2009)

5. Airqualitynews.com: Pollution from HGVs 'Costs Europe Nearly $£ 40$ Billion (2013) (online). http://www.airqualitynews.com/ 2013/02/28/pollution-from-hgvs-costs-europe-nearly-40-billion. Accessed 14 Mar 2017

6. Cenex-Atkins: Low Carbon Truck and Refuelling Infrastructure Demonstration Trial Evaluation-First Annual Report to the DfT Executive Summary for publication, UK (2014)

7. European Commission: A Call to Action on Urban Logistics. Brussels (2013)

8. Taniguchi E, Thompson RG, Yamada T (2014) Recent trends and innovations in modelling city logistics. Proc. Soc. Behav. Sci. 125:4-14

9. Diziain D, Taniguchi E, Dablanc L (2014) Urban logistics by rail and waterways in France and Japan. Soc. Behav. Sci. 125:159-170

10. Dampier A, Marinov M (2015) A Study of the Feasibility and Potential Implementation of Metro-Based Freight Transportation in Newcastle upon Tyne. Springer, Newcastle Upon Tyne

11. Wallace School of Transport: What is the Difference Between LGV Training and HGV Training? (2016) (online). http://www. wallaceschool.co.uk/blog/HGV_or_LGV. Accessed 14 Feb 2017

12. HMRC: Department for Transport, Licensed Heavy Goods Vehicles, by Region: Great Britain and United Kingdom (2016) (online). https://www.gov.uk/government/statistical-data-sets/ veh05-licensed-heavy-goods-vehicles. Accessed 12 Apr 2017

13. HMRC: Moving goods by road (2016) (online). https://www.gov. uk/guidance/moving-goods-by-road. Accessed 09 Apr 2017

14. Campaign for Better Transport: Air Pollution Matters (online). http://www.bettertransport.org.uk/air-pollution-matters. Accessed 10 Apr 2017

15. Crainic TG, Ricciardi N, Storchi G (2004) Advanced freight transportation systems for congested urban areas. Transp. Res. Part C 12:119-137

16. Transport for London: Electric Vehicles (2016) (online). https:// tfl.gov.uk/modes/driving/electric-vehicles. Accessed 16 Apr 2017
17. Dutch Amsterdam: Amsterdam to Get Freight Trams (2007) (online). http://www.dutchamsterdam.nl/207-207. Accessed 16 Feb 2017

18. Shen, J., Qiu, F., Li, W., Feng, P.: A new urban logistics transport system based on a public transit service. In: CICTP, pp. 651-661 (2015)

19. Department for Transport: The Pathway to Driverless Cars: A Detailed Review of Regulations for Automated Vehicle Technologies, UK (2015)

20. Flickr: Tyne and Wear Metro (2013) (online). https://www.flickr. com/photos/emdjt42/10870475016. Accessed 16 Feb 2017

21. Monash University: An Innovative Approach to Metropolitan Train Carriage Interior Configuration-To Improve Boarding, Alighting, Dwell Time, Stability and Passenger Experience, Melbourne (2013)

22. 123 Royalty Free: London Underground (2017) (online). https:// www.123rf.com/photo_18402815_interior-from-london-undergroundtrain.html. Accessed 13 Feb 2017

23. Coxon, S., Burns, K., de Bono, A, Napper, R.: An Examination of Three Approaches to Metro Rolling Stock Design to Ameliorate Extended Dwell Times Due to Passenger Growth and Associated Crowding. Institute of Transport Studies, Monash University (2011)

24. Nexus: Metro Strategy 2030 (2014) (online). http://www.nexus. org.uk/sites/default/files/Metro\%20Strategy $\% 202030 \% 20$ summary \%20document.pdf. Accessed 19 Apr 2017

25. Wikiwand: Tyne and Wear Metro Rolling Stock (online Blog). http://www.wikiwand.com/en/Tyne_and_Wear_Metro_rolling_ stock. Accessed 17 Feb 2017

26. Marinov, M., Toal, J.: A Study by Product Design into the Potential for a Check-In and Bag Drop. Newcastle upon Tyne (2016)

27. Railway-technology.com: Tyne and Wear Metro, UK (online). http://www.railway-technology.com/projects/tyne/. Accessed 19 Apr 2017

28. Marcle Leisure: Seat Bed Mechanism for Motor Homes and Caravans (online). http://www.marcle-leisure.co.uk/information/ rock-n-roll-hinges.htm. Accessed 20 Mar 2017

29. Rockwell Collins: B/E Aerospace (2016) (online). http://beaero space.com/. Accessed 02 Mar 2017

30. Telegraph, T.: Legroom Wars: The Seat to Change it All (2017) (online). http://www.telegraph.co.uk/travel/news/Legroom-warsthe-seat-to-change-it-all/. Accessed 02 Mar 2017

31. How Stuff Works: How RFID Works (2017) (online). http:// electronics.howstuffworks.com/gadgets/high-tech-gadgets/rfid. htm. Accessed 08 Apr 2017

32. Motion Controls Robotics: Automatic Guided Carts (AGCs) End-of-Line Automation-Integrated Material Handling Systems (online). http://motioncontrolsrobotics.com/robotic-applications/ automated-material-handling/automatic-guided-carts-agc/. Accessed 08 Mar 2017

33. Technovelgy.com: What is RFID? (online). http://www.techno velgy.com/ct/technology-article.asp. Accessed 06 Apr 2017

34. Browning R, Parker E, Herron J, Kram R (2006) Effects of obesity and sex on the energetic cost and preferred speed of walking. J. Appl. Physiol. 100:390-398

35. The Journal: Bakery giant Greggs opens doors on $£ 16.5 \mathrm{~m}$ site (2011) (online). http://www.thejournal.co.uk/business/businessnews/bakery-giant-greggs-opens-doors-4417628. Accessed 25 Feb 2017

36. Traffic Technology International: Autonomous Vehicle Safety Regulation World Congress 2017 (2017) (online). http://www. autonomousregulationscongress.com/. Accessed 14 Apr 2017

37. Frevue: Freight Electric Vehicles in Urban Europe (2016) (online). http://frevue.eu. Accessed 16 Feb 2017 
38. Maes, J.; Vanelslander, T.: The Use of Urban Rail Transport as Part of the Supply Chain in an Urban Logistics Context, Lisbon (2010)

39. Brice D, Marinov M, Rüger B (2015) A newly designed baggage transfer system implemented using event-based simulations. Urban Rail Transit 1(4):194-214
40. Marinov M, Giubilei F, Gerhardt M, Özkan T, Stergiou E, Papadopol M, Cabecinha L (2013) Urban freight movement by rail. J Transp Lit 7(3):87-116 